\title{
Studies on the Physico-Chemical Properties of Siyal Kanta (Argemone mexicana linn) Seed Oil
}

\author{
G. M. Ahmed, M. S. Rahman, M. R. Zaman, M. A. Hossain, M. M. Uddin and S. Yeasmin \\ Bangladesh Council of Scientific and Industrial Research Laboratories, Rajshahi.
}

\begin{abstract}
The physico-chemical properties of the extracted oil were studied by the conventional methods. It was observed that Siyal Kanta grown under the soil and climatic condition of Bangladesh contains about $35 \%$ of pale yellow coloured oil. The total lipids were fractionated into three major lipid groups, neutral lipids, glycolipid and phospholipids by silicic acid column chromatography. Among the lipids, the neutral lipids were varied from 92.1-92.3\%, glycolipid 5.5-5.8\% and phospholipid 1.5-1.7\% of the total oil of the lipid applied. The oil was also fractionated into mono-, di- and triglyceride by silicic acid column chromatography. The triglycerides were varied from $90.1-90.3 \%$, diglycerides from $2.3-2.8 \%$ and monoglycerides from $1.5-1.8 \%$. The saturated and unsaturated fatty acids present in the oil were separated and found to be $14.2-14.5 \%$ and $84.2-84.8 \%$ respectively depending on the areas in which the plant grows. The fatty acid compositions of the oil were analyzed by Gas Liquid Chromatography (GLC). The major fatty acids found in the oil were oleic acid (23\%), linoleic acid (58\%), palmetic acid (7\%) and ricinoleic acid (10\%).
\end{abstract}

Key words: Siyal kanta seed oil, Glyceride, Lipid and Fatty acid.

\section{Introduction}

Siyal kanta (Argemone mexicana linn.) is an annual herb plant with prickly stem which belongs to the family papaveraceae. The plant was originated in tropical America. Now it thrives well in India, Pakistan and Bangladesh. The plant reaches a height of 2-3 ft and generally it is grown mixed with other crops in sandy loom soil. The plant flowers during the month of March-April and sets fruits in the month of May-June. The juice of the plant is used as a remedy for dropsy, jaundice and skin diseases (Mukherjyee et al 1950). The plants bear a good number of bristly capsules containing a lot of seeds resembling black mustard seed which are demulcent, laxative, nauseat and expectorant (Goni 1998). Its seed contains about $34-38 \%$ non edible oil and possesses a semi drying property (Thorpe et. al.1949, Hill 1951). The compositions of oil vary with the source and depend on some factors such as climatic conditions, soil type and the maturity of the plant (Sallans 1964). The oil is used as an illuminate, lubricant and as fuel in lamps, medicines, ulcers and eruption (Anon 1948, Watt 1972).

The physico-chemical properties of the oil are directly related to their lipids and glyceride compositions (Rahman et. al.2002). So, knowledge on the compositional factors is very essential in connection with the properties. The present work had been undertaken to carry on the physico-chemical properties, lipids and glyceride composition of Siyal Kanta seed oil.

\section{Materials and Methods}

Ripe and matured Siyal kanta seeds were collected from the district of Rajshahi, Pabna and Dinajpur. The seeds were then dishelled manually and the kernels thus obtained were crushed into smaller particles in a glass mortar and dried in the oven at a temperature of $105^{\circ} \mathrm{C}$ for about $1 / 2$ an hour to about $4-6 \%$ moisture. The moisture content in the fresh kernels was determined by IUPAC method (Anon 1979). The oil was then extracted with n-hexane in a Soxhlet apparatus for 8 hours. $n$-hexane as extracted solvent has been selected because the solvent has better effect over other polar solvents like alcohol, ketone, aldehyde, ether and ester etc (Ali et. al. 1996). The oil was recovered by the evaporation of the solvent under reduced pressure using a rotary vacuum evaporator and the percentage of oil content was calculated. The percentage of free fatty acid (FFA), saponification value, peroxide value and unsaponifiable matters in the oils were determined by the standard AOCS method (Anon 1955). Hanus method was followed to determine the iodine value of the oils (Anon 1980).

\section{Separation of Lipid Classes by Column Chromatography}

The major lipids classes of the oil were fractionated by silicic acid (E. Merck, Darmastad, Germany, 70-230 mesh) column chromatography (Rouser et al 1966). The silicic acid 
was washed with $5 \%(\mathrm{w} / \mathrm{w})$ water and methanol to remove fines and impurities. It was activated at $120^{\circ} \mathrm{C}$ overnight and again for 1 hour immediately before the column was prepared. For each column $25 \mathrm{~g}$. silicic acid was washed with $250 \mathrm{ml}$ of chloroform/ methanol $(7: 1 \mathrm{v} / \mathrm{v}), 120 \mathrm{ml}$ chloroform $/$ methanol $(15: 1 \mathrm{v} / \mathrm{v})$ and $160 \mathrm{ml}$ chloroform. A slurry of 25 g. of silicic acid in chloroform was poured into the column $(2.2 \mathrm{~cm}$ i. d). $150 \mathrm{mg}$ total lipids were dissolved in $5 \mathrm{ml}$ eluting solvent and quantitatively transferred to the column.

The neutral lipid was eluted with chloroform, glycolipids with acetone and phospholipids with methanol (Ali el. al.1997). The elution was controlled with a flow rate of 1.5$2.0 \mathrm{ml} / \mathrm{min}$. The elution of each fraction was monitored by micro-slide Thin Layer Chromatography (TLC) to ensure uniformity of separation of each lipid class during silicic acid chromatography and the eluted solvents were collected in a weight flask. The fractions thus obtained were evaporated in a rotary vacuum evaporator and were dried under reduced pressure before being weighed. The lipid classes were identified by $\mathrm{R}_{\mathrm{f}}$ comparison with standard references. The percentages of these fractions were determined by gravimetric method.

\section{Separation of glycerides}

The whole oil was separated into mono-, di and triglycerides on silicic acid column (E.Merck, Darmstad, Germany, 70230 mesh) column. The silicic acid was activated at $120^{\circ} \mathrm{C}$ over night and again for $1 \mathrm{hr}$. immediately before the column was prepared. Then the silicic acid was hydrated with $5 \%$ water. A slurry of $25 \mathrm{~g}$. of silicic acid in chloroform was poured into the column $(2.2 \mathrm{~cm}$. i.d). $1 \mathrm{~g}$. of oil was dissolved in $15 \mathrm{ml}$. of chloroform and quantitatively transferred to the column. The triglyceride was eluted with $200 \mathrm{ml}$. of benzene, diglyceride with $200 \mathrm{ml}$. of a $1: 9 \mathrm{v} / \mathrm{v}$ mixture of diethyl ether and benzene and monoglyceride with $200 \mathrm{ml}$. of diethyl ether (Gafur et. al.1993). The elution was controlled at a flow rate of $1.5-2 \mathrm{ml} . / \mathrm{min}$.

The elution of each fraction was monitored by micro-slide thin layer chromatography (TLC) to ensure uniformity of separation of each class of glyceride during silicic acid chromatography and the eluted solvents were collected in a weighed flask. The fractions thus obtained were evaporated in a rotary evaporator and were dried under reduced pressure before being weighted. The glyceride classes were identified by comparison of $\mathrm{R}_{\mathrm{f}}$ values with standard references. The percentage of each glyceride class was calculated by gravimetric method.

\section{Analysis of fatty acid composition}

To know the nature of the fatty acid composition present in the siyal kanta seed oil of the sample of Rajshahi district were analyzed as their methyl esters, which were prepared by the Boron trifluride methanol method (Mondol et.al. 2006). A GCD Pye Unicam Gas chromatographed equipped with a flame ionization detector was used to determined the fatty acid methyl ester. Nitrogen carrier gas was used at a flow rate $30 \mathrm{ml} / \mathrm{mm}$. Fatty acids were separated on a $1.8 \mathrm{~m} \mathrm{X}$ $2 \mathrm{~mm}$ i. d. glass column packed with $6 \%$ BDS (Butanediol Succinate Polyesters) on solid support Anakrom ABS 100/120 mesh. Analysis was carried out at isothermal column temperature of $190{ }^{\circ} \mathrm{C}$, injector and detector temperature for all GLC analysis were $230^{\circ} \mathrm{C}$. The peaks were identified by comparison with standard methyl esters for retention times by plotting the log of retention time against equivalent carbon length (ECL). The peak areas were determined by multiplying peak height by width at half height. The percentage of each peak was calculated as the percentage of the total area of all the peaks.

\section{Separation of saturated and unsaturated fatty acids in Siyal kanta seed oil}

Separation of saturated and unsaturated fatty acids was carried out by Lead-salt ether method (Das, 1989) on about 50g. of oil. The oil was saponified with alcoholic caustic soda to obtain soap solution. An excess of lead acetate solution was added to the soap solution to form a mixture of lead salts of fatty acids which were then separated by filtration. Diethyl ether was added to the mixture of lead salt and the whole mixture was boiled for 15 minutes and then cooled at $0^{\circ} \mathrm{C}$ for 24 hours. The precipitated lead salts of saturated fatty acids so formed were separated from the solution of lead salts of unsaturated fatty acids by filtration. The lead salts of unsaturated fatty acids were obtained by removing the ether from the ethereal solution. Each group of lead salts was suspended in water and treated with sufficient hydrochloric acid (35\%) to form fatty acids and lead chlorides. The mixture was then extracted with ether to obtain the ethereal solution of each group. On evaporating the ether the fatty acids were obtained in separated group. Finally masses of saturated and unsaturated fatty acids were obtained by weighing them separately.

\section{Results and Discussion}

Siyal kanta seed kernels were collected from three different districts and the oil had been extracted by n-hexane to evaluate the physico-chemical characteristics, lipids and glyceride compositions. The physico-chemical characteristics of the extracted oils were determined by the conventional meth- 
ods and the results were shown in Table I. The results (Table I) indicated that no significant difference in physico-chemical characteristics among the three samples collected in three different districts was observed. The saponification values and unsaponifiable matters of the oil more or less agree with the reported results of Tobacco seed oil (Gofur et. al. 1993). Specific gravity and refractive index of the oils were comparable with those of important vegetable oils (Hilditch, 1949). were presented in Table II. From the result it was evident that diglycerides in the oil sample of Dinajpur district were found to be higher in comparison with other two samples. No appreciable changes of triglycerides was observed among the three samples and from the results it was observed that triglycerides in all the three samples irrespective of origin accounted for over $90 \%$ of the total weight of the lipid.

Table I: Physico-chemical properties of Siyal kanta seed oil \pm SE

\begin{tabular}{|c|c|c|c|c|}
\hline & \multirow[t]{2}{*}{ Physical and chemical properties } & \multicolumn{3}{|c|}{ Origin } \\
\hline & & Rajshahi & Pabna & Dinajpur \\
\hline 1. & Percentage of oil & $35 \pm 0.0348$ & $34.8 \pm 0.0345$ & $34.5 \pm 0.0343$ \\
\hline 2. & Moisture and volatile matter (\%) & $4.5 \pm 0.047$ & $4.2 \pm 0.042$ & $4.3 \pm 0.045$ \\
\hline 3. & Specific gravity at $28^{\circ} \mathrm{C}$ & $0.920 \pm 0.001$ & $0.918 \pm 0.001$ & $0.921 \pm 0.001$ \\
\hline 4. & Refractive Index at $28^{\circ} \mathrm{C}$ & $1.4580 \pm 0.005$ & $1.4579 \pm 0.005$ & $1.4581 \pm 0.005$ \\
\hline 5. & Free fatty acid as oleic (\%) & $5.2 \pm 0.0577$ & $5.1 \pm 0.0570$ & $5.2 \pm 0.0 .75$ \\
\hline 6. & Iodine value & $118 \pm 1.527$ & $118 \pm 1.527$ & $119 \pm 1.528$ \\
\hline 7. & Saponification value & $188 \pm 0.5575$ & $187.5 \pm 0.5573$ & $187.8 \pm 0.5575$ \\
\hline 8. & Unsaponifiable matter (\%) & $1.5 \pm 0.115$ & $1.2 \pm 0.112$ & $1.3 \pm 1.11$ \\
\hline 9. & Peroxide value meqv. $/ \mathrm{kg}$ & $1.20 \pm 0.112$ & $1.18 \pm 0.110$ & $1.21 \pm 0.112$ \\
\hline
\end{tabular}

Mean value of three experimental results

Total extracted Siyal kanta seed lipids were separated into neutral lipids, glycolipids and phospholipids by silicic acid column and results were depicted in Table II. The results (Table II) indicated that no significant change in the lipid composition among the three samples was noticed. But it is remarkable to note that the percentages of phospholipids (Table II) were found to be very higher (1.5-1.71) in comparison with other vegetable oils (Ali et. al. 1985, Uddin et. al. 2007, Rahman et. al. 2004, 2007). From results shown in Table II, it was observed that the neutral lipids were averaged to over $92 \%$ of the total weight of the lipid applied.

The whole oil was fractionated into mono-, di- and triglycerides by means of column chromatography and the results

Table II: Glycerides, lipids and fatty acids of Siyal Kanta seed oil (\%) \pm SE

\begin{tabular}{l|l|l|l}
\hline Compositions & Rajshahi & Pabna & Dinajpur \\
\hline Mono-glyceride & $1.8 \pm 0.115$ & $1.5 \pm 0.112$ & $1.7 \pm 0.114$ \\
Di-glyceride & $2.5 \pm 0.172$ & $2.3 \pm 0.170$ & $2.8 \pm 0.175$ \\
Tri-glyceride & $90.3 \pm 0.057$ & $90.1 \pm 0.054$ & $90.2 \pm 0.055$ \\
FFA & $5.2 \pm 0057$ & $5.1 \pm 0.055$ & $5.0 \pm 0.053$ \\
Neutral lipid & $92.3 \pm 0.252$ & $92.1 \pm 0.250$ & $92.2 \pm 0.251$ \\
Glycolipid & $5.8 \pm 0.117$ & $5.5 \pm 0.113$ & $5.7 \pm 0.115$ \\
Phospholipid & $1.5 \pm 0.100$ & $1.7 \pm 0.115$ & $1.7 \pm 0.115$ \\
Saturated fatty acid & $14.2 \pm 0.055$ & $14.5 \pm 0.057$ & $14.4 \pm 0.055$ \\
Unsaturated fatty acid & $84.8 \pm 0.5775$ & $84.2 \pm 0.5772$ & $84.3 \pm 0.5773$ \\
\hline
\end{tabular}

The saturated and unsaturated fatty acids present in the oils were separated by Lead-Salt ether method and the results were shown in Table II. From the results, it was observed that the percentages of saturated and unsaturated fatty acids present in the oil samples of Pabna and Dinajpur districts were almost similar, but a slight variation was noticed in the sample of Rajshahi district which proves it to be slightly better than those of other two samples.

To know the nature of the fatty acid composition present in the Siyal kanta seed oil, one of the samples (sample of Rajshahi district) was analyzed by GLC and the results were shown in Table III. Gas chromatographic analysis showed that unsaturated fatty acids present in the siyal kanta seed oil were mainly linoleic $(58 \%)$ and oleic $(23 \%)$ acids, which altogether accounted for $81 \%$ of the total fatty acids.

Table III: Fatty acids compositions of Siyal Kanta seed oil \pm SE

\begin{tabular}{l|l}
\hline Fatty acids & Weight percent \\
\hline Oleic acid & $23.00 \pm 0.05877$ \\
Linoleic acid & $58.00 \pm 0.05773$ \\
Palmetic acd & $7.00 \pm 0.1877$ \\
Ricinoleic acid & $10.00 \pm 0.02023$ \\
\hline
\end{tabular}




\section{Conclusion}

As Siyal kanta seed contains about 35\% non-conventional oil, so it may be considered as one of the important sources of non-edible oil. At present, Bangladesh is facing acute shortage of edible and non-edible industrial oils. So, it is compelled to import edible and non-edible oils from abroad. Under these circumstances, Siyal kanta seed oil can play a vital role in bridging the vegetable oil gap in the country. Moreover the oil is suitable for the manufacture of paint, varnishes and soap as the oil rich in linoleic acid and higher saponification value.

\section{Acknowledgement}

The authors express their gratitude to Director, BCSIR Laboratories, Rajshahi for providing necessary laboratory facilities.

\section{References}

Anon. (1955). Association of Official Agricultural Chemists; Official Methods of Analysis, Washington, 8th edition, 468-470.

Anon. (1979). International Union of Pure and Applied Chemistry, Standard Methods for the Analysis of Oils, Fats and Derivatives, 6th edition, Pergamon Press, 126-127.

Anon. (1980). Official and Tentative Methods of the American Oil Chemists Society, Part I and II, Champaign, IL, Chicago, 3rd edition, 115-120.

Anon. (1948). The Wealth of India, A Dictionary of Indian Raw Materials and Industrial Products, Publications and Information Directorate, CSIR, New Delhi, I:116.

Ali M. H., Rahman M. S., Ahmed G. M., Hossain M. A. and Uddin M. A. (1997). Studies on the effect of different solvent mixture for the extraction of ground nut seed lipids. Bangladesh J. Sc. Ind. Res, 32(2): 166-171.

Ali M. H., Rahman M. S., Ahmed G. M., Hossain M. A. and Uddin M. A. (1996). The effect of packing materials on the stability of ground nut oil during storage Bangladesh J. Sc. Ind. Res, 31(3): 59-67.

Ali M.A., Gofur M. A, Rahman M. S. and Ahmed G. M. (1985). Variations in fat content and lipid class composition in ten different mango varieties. JAOCS, 62 (3): 520.

Das R. K. (1989). Industrial Chemistry, Part-2, Kalyani Publishers, New Delhi, India, 279-282.

Gani A. (1998). Medicinal plant of Bangladesh, Asiatic Society of Bangladesh, Dhaka, 285-286.
Gofur M. A, Rahman M. S, Ahmed G. M Hossain A. and Haque M. E. (1993). Studies on the characterization and glyceride composition of Tobacco Seed Oil, Bangladesh J. Sc. Ind. Res, 27 (3): 27-28.

Hilditch T. P. (1949). The Industrial Chemistry of the Fats and Waxes, 3rd Edition, Bailliere Tindall and Cox, London, 80-83.

Hil A. F. (1951). Economic Botany 2nd Edition, Mc.GrawHil Book Company, London,199.

Mondol M. I., Khaleque M. A, Hossain M. A. and Hye M. A (2006). Studies on the preparation of powerful Phenyl from Petuli Seed Oil, Bangladesh J. Sc. Ind. Res, 41(34): 203-206.

Mukherjee S, Biswas K. and Ghose S. (1950), Barotio Bonoushodi, part-1: 63.

Rouser G. and Kritchevsky G. (1966). Lipid Chromatographic Analysis, Plenum Pulishing Co. Ltd., London, 1: 99-112.

Rahman M. S., Ali M. H., Hossain M. A. and Uddin M. M. (2002). Studies on the fatty acid and glyceride composition of Latkon Seed Oil, Bangladesh J. Sc. Ind. Res, 37(1-4): 33-40.

Rahman M. S., Ali, M. H., Hossain M. A. and Uddin M. M. (2004). Variations in oil content and lipid class composition in five different groundnut varieties, Bangladesh J. Sc. Ind. Res, 39(1-2): 89-94.

Rahman M. S., Hossain M. A., Ahmed G. M. and Uddin M. M. (2007). Studies on the characterization lipids and glyceride composition of sesame Seed Oil, Bangladesh J. Sc. Ind. Res, 42(1) : 67-74.

Sallans H. R. (1964). Factors Affecting the Composition of Canadian Oil Seeds. JAOCS, 41: 215-218.

Thorpe J. F and Whitely M. A (1949). Thorp's Dictionary of Applied Chemistry, 4th Edition, Longmans, Green and Co. Ltd. London, 9: 27.

Uddin M. M., Rahman, M. S., Ahmed, G. M., Hossain, M. A. and Samad A. (2007). Variation in lipid content and glyceride compositions of four different varieties of corn oil. Bangladesh J. Sc. Ind. Res, 42 (2): 223-228.

Watt G. (1972). A Dictionary of the Economic Product of India, International Book Distribution, India, 1: 306.

Received: January, 13, 2010;

Accepted : April 25, 2011 